\title{
Fine structural changes in the fibroblasts of canine heart valves prepared for grafting
}

\author{
J. B. GAVIN ${ }^{1}, J$. L. MONRO, F. M. WA L L, a nd \\ S. C. W. CHALCR OF T \\ Department of Pathology, University of Auckland and Cardiothoracic Surgical Unit, \\ Green Lane Hospital, Auckland, New Zealand
}

\begin{abstract}
Gavin, J. B., Monro, J. L., Wall, F. M., and Chalcroft, S. C. W. (1973). Thorax, 28, 748-755. Fine structural changes in the fibroblasts of canine heart valves prepared for grafting. Fibroblasts in canine heart valves were examined by light and electron microscopy after one, two, and three weeks' exposure to Hanks's balanced salt solution and to three series of antibiotic solutions used in preparing heart valve allografts. Condensation of chromatin, degeneration of mitochondria, dilatation and loss of endoplasmic reticulum, and rupture of cellular membranes were observed in a proportion of fibroblasts exposed to Hanks's solution for longer than one week and in all specimens treated with antibiotics. These changes became more frequent and severe as the exposure to these solutions increased and they were not reversed nor inhibited by the inclusion of a tissue culture medium in the mixture. These findings are discussed in relation to the role of donor fibroblasts in heart valve allografts.
\end{abstract}

The good clinical results obtained when semilunar heart valves are removed from cadavers under sterile conditions and used as allografts have led some authors (Kosek, Iben, Shumway, and Angell, 1969; Angell, Shumway, and Kosek, 1972) to suggest that the continued survival and function of donor fibroblasts may prolong the survival of heart valve allografts. However, it is virtually impossible to obtain an adequate supply of such 'fresh' or 'untreated' valves. The valves usually used as allografts are obtained at routine necropsy, and therefore they require some form of sterilization before use. While chemical methods of sterilization are known to destroy all donor cells (Hudson, 1966 ; Gavin, Herdson, and Barratt-Boyes, 1972) milder forms of treatment with various combinations of antibiotics may not (Angell, Mermet, and Buch, 1970; Al-Janabi, Gonzalez-Lavin, Neirotti, and Ross, 1972 ; Lockey, Al-Janabi, Gonzalez-Lavin, and Ross, 1972).

This paper reports and discusses the fine structural changes which occur in the fibroblasts of canine heart valves prepared as allografts using various antibiotic solutions.

1Address for reprints: Dr. J. B. Gavin, Department of Pathology, University of Auckland, Private Bag, Auckland, New Zealand.

\section{MATERIAL AND METHODS}

Aortic and pulmonary valves were collected under sterile conditions from five mongrel dogs immediately after they were killed. Each valve was divided into three at the commissures, rinsed briefly in Hanks's (1948) balanced salt solution and the segments were placed in individual sterile containers. These were divided into five groups each containing three aortic and three pulmonary valve segments. The groups were treated as follows:

GROUP 1 Immediately fixed for microscopic examination with phosphate-buffered (pH 7.4) $5 \%$ glutaraldehyde solution at $4^{\circ} \mathrm{C}$ to provide control data.

GROUP 2 Stored in Hanks's balanced salt solution at $4^{\circ} \mathrm{C}$ and therefore termed 'fresh' or 'untreated' allografts.

GROUP 3 Stored in Hanks's balanced salt solution containing 50 units of penicillin, $1 \mathrm{mg}$ streptomycin, 1 $\mathrm{mg}$ of kanamycin and $25 \mu \mathrm{g}$ of amphotericin B in each millilitre of solution. This solution was replaced after four days. After another four days it was replaced by Hanks's balanced salt solution per se. This is the method used until recently at Green Lane Hospital (Barratt-Boyes and Roche, 1969).

GROUP 4 Incubated for three hours at $37^{\circ} \mathrm{C}$ in 
Hanks's balanced salt solution containing $50 \mu \mathrm{g}$ each of gentamicin, colistin (Coly-Mycin), kanamycin, and lincomycin and $10 \mu \mathrm{g}$ of amphotericin B in each millilitre of solution. Incubation was continued for a further 21 hours at $37^{\circ} \mathrm{C}$ in Hanks's balanced salt solution supplemented with $40 \mu \mathrm{g}$ of gentamicin and lincomycin and $10 \mu \mathrm{g}$ of amphotericin B per millilitre. Tissue was then stored at $4^{\circ} \mathrm{C}$ in Hanks's balanced salt solution per se. This is a method similar to that used by Angell, de Lanerolle, and Shumway (1973).

GROUP 5 Placed in tissue culture medium 199 (Commonwealth Serum Laboratories, Melbourne, Australia) to which was added the same concentration of antibiotics used for group 3 plus phenol red indicator. This solution was changed after four days. After another four days it was replaced by medium 199 , to which was added $10 \%$ fetal calf serum, and stored at $4^{\circ} \mathrm{C}$. This is a modification of the method of Barratt-Boyes and is currently in use at Green Lane Hospital.

Segments of pulmonary and aortic valves from groups 2 to 5 were taken after 7, 14, and 21 days and immersed in 5\% glutaralydehyde. After 24 hours' fixation, samples were excised from the cusps of all valve segments. These were then washed and postfixed in phosphate-buffered $1 \%$ osmium tetroxide for one hour. After the tissue blocks had been embedded in epoxy resin they were sectioned, stained with uranium and lead salts, and examined with a Philips EM300 electron microscope. Photomicrographs were prepared not only of representative cells but also of 15 consecutively observed fibroblasts from each specimen.

The remainder of each segment was embedded in paraffin wax and 7 micron sections were prepared for light microscopic examination. Successive sections were stained with haematoxylin and eosin, van Gieson's stain, Weigert's elastin stain, and alcian blue at $\mathrm{pH} 1.0$ and $2 \cdot 5$.

\section{RESULTS}

The valves contained numerous fibroblasts which lay in a matrix of collagenous and elastic fibres and were covered by a single layer of flattened endothelial cells. All had a normal architecture and were free of overt pathology. Aortic valve leaflets were generally thicker than those of the corresponding pulmonary valve but their structural components were similar. Although there was some interfibrillar oedema and a patchy loss of endothelial cells in some valves in all groups stored longer than seven days, it was not possible by light microscopy to distinguish between the various groups.

With the electron microscope normal fibroblasts were seen to be irregular in outline. They lay among typical, transversely striated collagen fibres and larger, amorphous elastin fibres from which fine fibrils radiated. Their nuclei were ovoid and frequently indented and showed a thin peripheral electron-dense layer of heterochromatin adjacent to the nuclear membrane with evenly granular euchromatin elsewhere (Fig. 1). The surrounding cytoplasm was moderately electron-dense and contained an even array of fine filaments which lay between the various organelles. Rounded or ovoid mitochondria contained a regular array of parallel cristae lying in a uniform, moderately dense matrix. Smooth-surfaced sacs and vesicles of Golgi apparatus were usually evident close to one pole of the nucleus (Fig. 1), while elements of the roughsurfaced endoplasmic reticulum with attached ribosomes were generally distributed more peripherally in the cytoplasm (Fig. 1). Occasional cells contained clear membrane-bound vacuoles or membranous figures, but these occurred singly and were uncommon. The cell outlines were sometimes indented by micropinocytotic invaginations but cell membranes were always intact.

In contrast, some or all of the fibroblasts in valves subjected to preservation procedures showed a variety of ultrastructural alterations. In some, chromatin was condensed into electrondense aggregations both centrally and peripherally within affected nuclei (Fig. 3) and in more severely affected cells there was also a loss of the intervening euchromatin (Figs. 6 and 8).

Lipid droplets (Fig. 2) were present in the cytoplasm of some cells. Others showed mitochondrial swelling and disorganization with distortion or disruption of cristae and loss of mitochondrial matrix (Fig. 4). Disappearance of Golgi apparatus and rough-surfaced endoplasmic reticulum was also observed. Cells affected by this latter change often contained membrane-bound vacuoles (Fig. 3) with a homogeneous or heterogeneous content of variable electron-density (Fig. 8).

Rupture of the cell plasma membranes was frequently observed and ranged from isolated small breaks with some loss of cytoplasmic filaments to extensive gaps with a marked loss of cytoplasm (Figs. 6 and 7). Some severely affected cells contained membranous structures, the origin of which was not clear.

The frequency with which these changes was observed after one, two, and three weeks in various media is indicated in the Table. While the changes in valves stored one week in Hanks's balanced salt solution were relatively mild and infrequent, they were progressively more frequent and more pronounced after two and three weeks. The fine structural alterations in all groups exposed to 


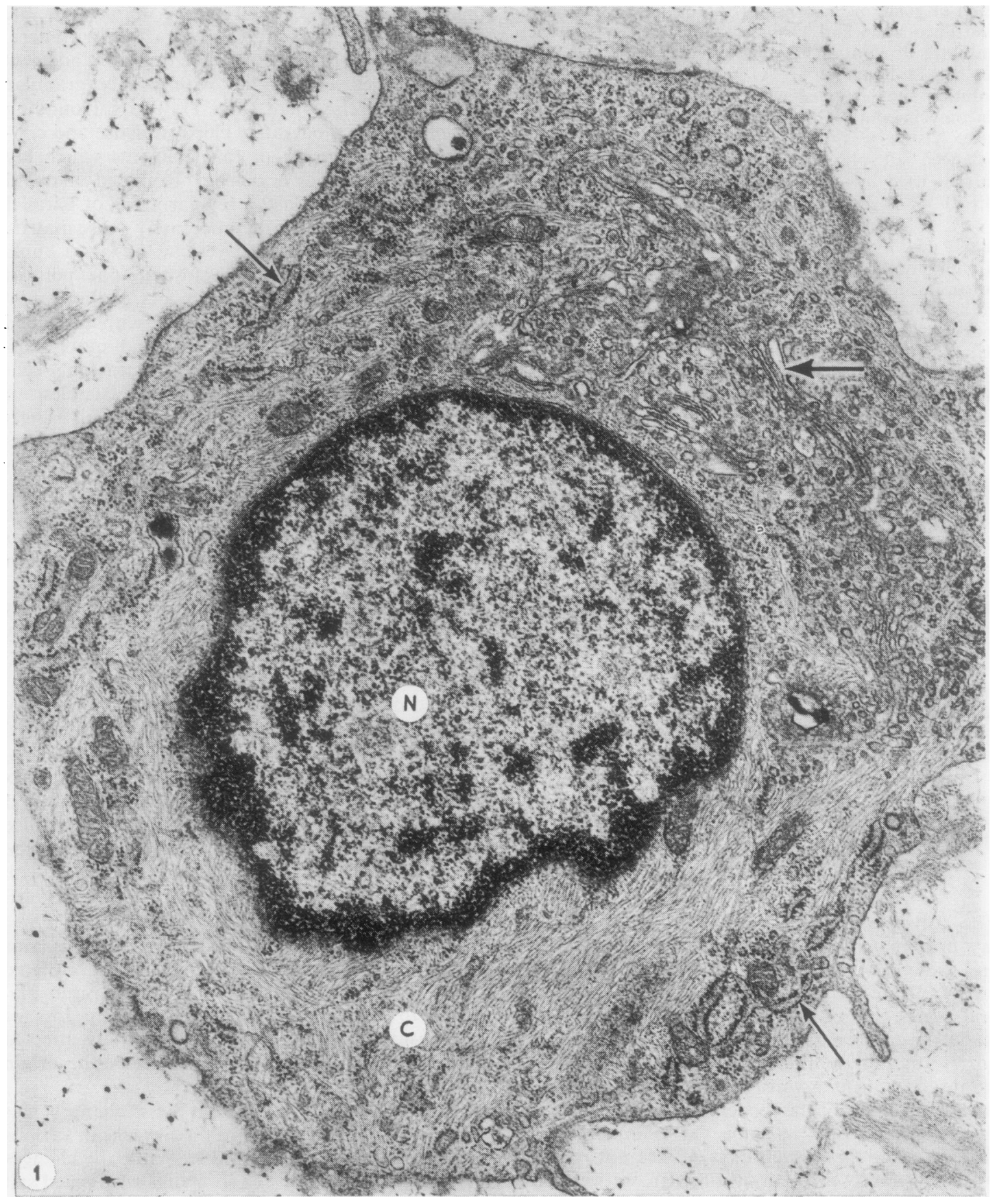

FIG. 1. A fibroblast from a normal canine aortic valve. The central nucleus has a peripheral band of dense heterochromatin surrounding granular euchromatin $(N)$. Elements of the Golgi apparatus (large arrow) and rough-surfaced endoplasmic reticulum (small arrows) are present in the filamentous cytoplasm (C). EM $\times 19,000$. 


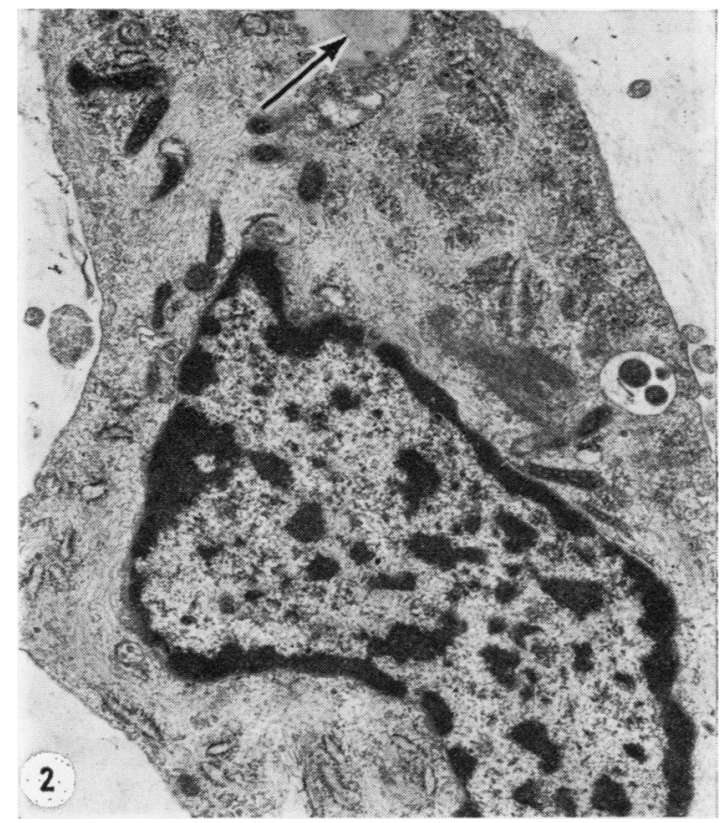

FIG. 2. A fibroblast after one week in Hanks's balanced salt solution. Apart from the large lipid droplet (arrow) this cell is similar to that in Fig. 1. EM $\times 10,000$.

FIG. 3. A fibroblast after one week in antibiotic medium (group 3). It contains large cytoplasmic vacuoles $(V)$ and shows condensation of nuclear chromatin (arrows). EM $\times 12,250$.

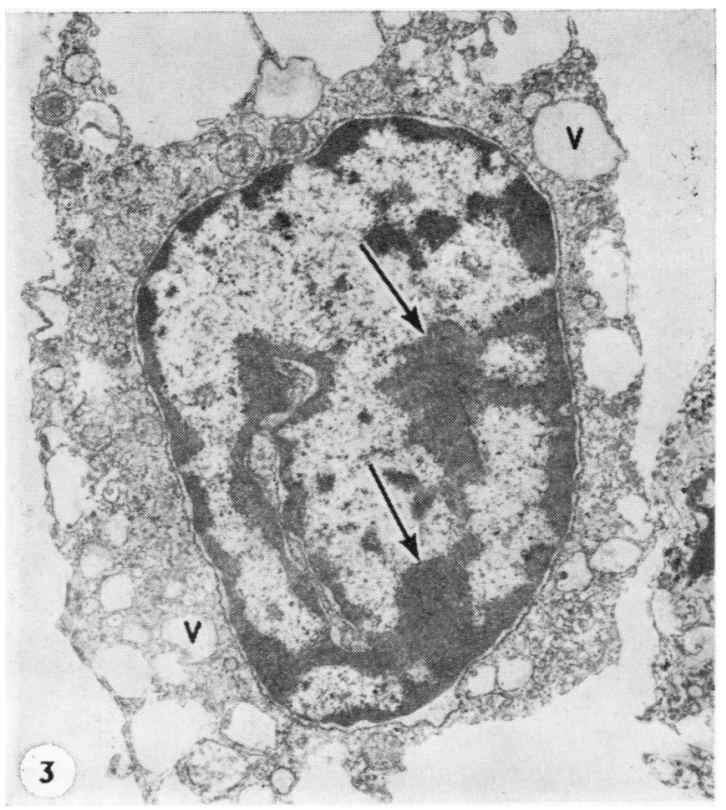




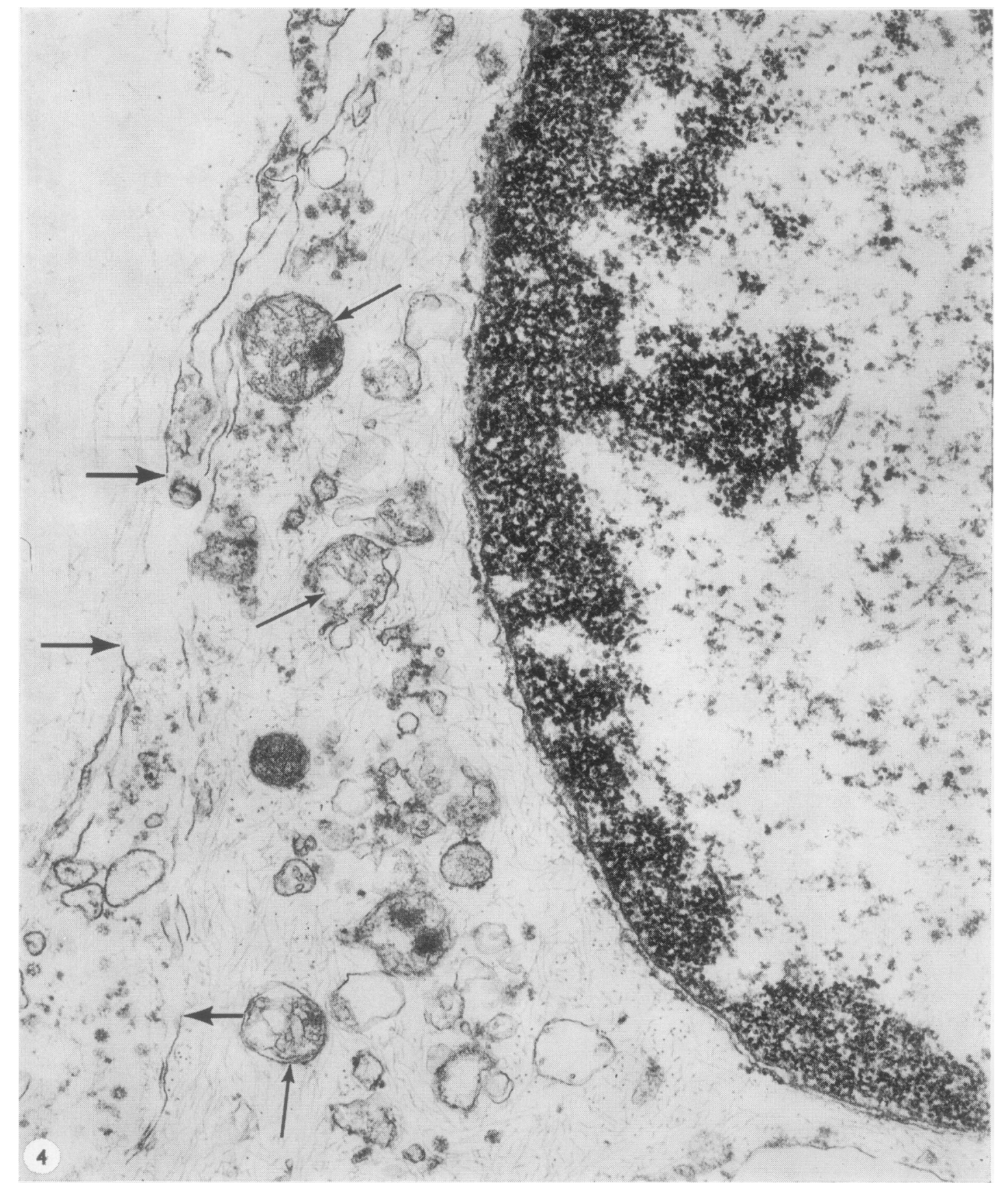

FIG. 4. A fibroblast after one week in antibiotic medium (group 4) showing degenerate mitochondria (small arrows) and rupture of the cell membrane (large arrows). $E M \times 28,000$. 

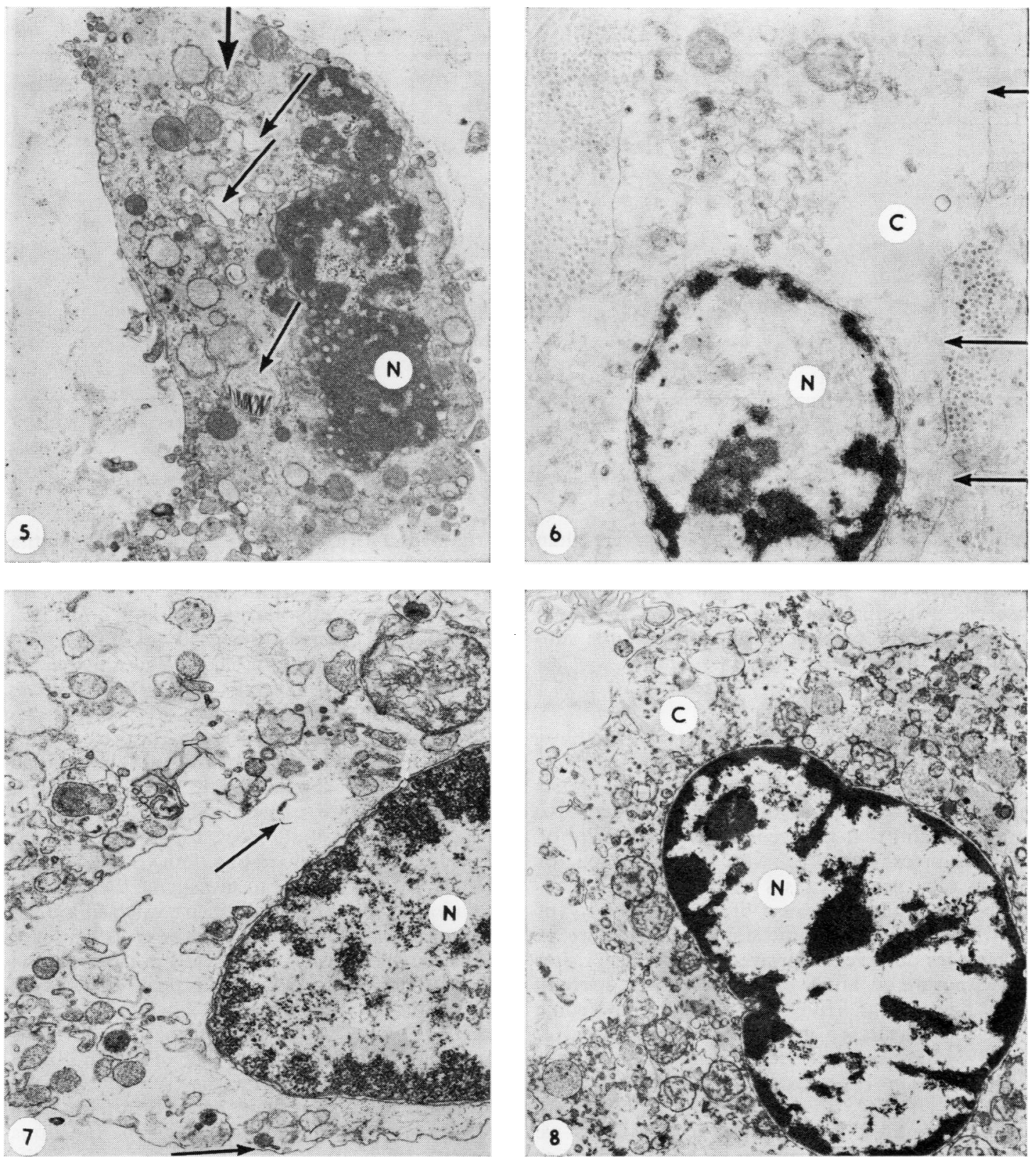

FIG. 5. A fibroblast after two weeks' storage in Hank's solution showing clumping of nuclear chromatin ( $N)$. vacuoles with heterogeneous contents (small arrows), and degeneration of mitochondria (lrge arrow). EM $\times 7,500$.

FIG. 6. A fibroblast after two weeks in antibiotics and tissue culture medium (group 5). There is a considerable loss of material from the nucleus $(N)$ and cytoplasm $(C)$ and there are extensive gaps in the cell membrane (arrows). EM $\times 10,000$. FIG. 7. A fibroblast after immersion for three weeks in Hanks's balanced salt solution, showing some loss of euchromatin from the nucleus $(N)$, disruption of cytoplasmic granules, and rupture of the cell membrane (arrows). EM $\times 12,250$. FIG. 8. A fibroblast after three weeks' exposure to Hanks's solution plus antibiotics (group 2) showing clumping of chromatin and a loss of euchromatin from the nucleus $(N)$ with degeneration of organelles and vacuolation within the cytoplasm (C). $E M \times 7,500$. 
T A B L E

PROPORTION OF CELLS IN VARIOUSLY TREATED GROUPS SHOWING FINE STRUCTURAL ALTERATIONS

\begin{tabular}{|c|c|c|c|c|c|c|c|}
\hline Group & $\begin{array}{l}\text { Cytoplasmic } \\
\text { Vacuolation }\end{array}$ & $\begin{array}{l}\text { Mitochondrial } \\
\text { Degeneration }\end{array}$ & $\begin{array}{l}\text { Condensation } \\
\text { of Chromatin }\end{array}$ & $\begin{array}{c}\text { Changes in Endo- } \\
\text { plasmic } \\
\text { Reticulum }\end{array}$ & $\begin{array}{c}\text { Loss of } \\
\text { Cytoplasm }\end{array}$ & $\begin{array}{l}\text { Rupture of } \\
\text { Cell Membrane }\end{array}$ & $\begin{array}{l}\text { Lipid } \\
\text { Droplets }\end{array}$ \\
\hline I & + & 0 & 0 & 0 & 0 & 0 & 0 \\
\hline $\begin{array}{c}\text { Week I } \\
\text { II } \\
\text { III } \\
\text { IV } \\
\text { V } \\
\text { Week } 2 \\
\text { II } \\
\text { III } \\
\text { IV } \\
\text { V } \\
\text { Week } 3 \\
\text { II } \\
\text { III } \\
\text { IV } \\
\text { V }\end{array}$ & $\begin{array}{l}+ \\
+ \\
+ \\
++ \\
+ \\
+++ \\
+ \\
++ \\
+++ \\
++\end{array}$ & $\begin{array}{l}+ \\
++ \\
+ \\
\text { All } \\
+ \\
++ \\
+++ \\
\text { All } \\
+++ \\
++++ \\
++++ \\
\text { All }\end{array}$ & $\begin{array}{l}+ \\
+++ \\
++ \\
++ \\
++ \\
+++ \\
+++ \\
++++ \\
++ \\
+++ \\
++++ \\
\text { All }\end{array}$ & $\begin{array}{l}+ \\
+++ \\
++++ \\
++ \\
+++ \\
+++ \\
++++ \\
++++ \\
+++ \\
++++ \\
++++ \\
\text { All }\end{array}$ & $\begin{array}{l}+ \\
++ \\
++ \\
+++ \\
++ \\
+++ \\
+++ \\
++++ \\
+++ \\
+++ \\
++++ \\
\text { All }\end{array}$ & $\begin{array}{l}0 \\
+ \\
+ \\
++++ \\
+ \\
++ \\
++ \\
+++ \\
++ \\
++ \\
++ \\
++++\end{array}$ & $\begin{array}{l}+ \\
+ \\
+ \\
+ \\
+ \\
+ \\
+ \\
+ \\
++ \\
+ \\
+\end{array}$ \\
\hline
\end{tabular}

$K E Y$ : Percentage of affected cells

antibiotics were more frequent and severe than those stored in Hanks's balanced salt solution. These changes were also more frequently observed with increased storage time and were not significantly inhibited or modified by the substitution of TC199 for Hanks's solution.

\section{DISCUSSION}

This study indicates that treatment with antibiotics can cause ultrastructural alterations in heart valve fibroblasts and that the frequency and severity of these changes increases with the duration of storage. The precise causes of these changes cannot be ascertained because of the complexity of the solutions used and the non-specific nature of the changes observed. However, it is not surprising that exposure to antibiotics of sufficient strength to kill bacterial and fungal cells should have some deleterious effects on mammalian cells. Angell $\boldsymbol{e t}$ al. (1973) have reduced the concentrations of antibiotics used in 1971 to minimize their effect on fibroblast viability.

While some of the ultrastructural changes we describe, such as the presence of lipid droplets or vacuoles, some swelling of mitochondria, and mild dilatation of smooth and rough endoplasmic reticulum, may be potentially reversible, others are not. Disruption of organelles or rupture of cell membranes with a loss of nuclear and cytoplasmic content must be considered lethal. The biochemical and functional significance of such ultrastructural changes has been extensively discussed elsewhere
(Trump and Ericsson, 1965 ; Trump and Arstila, 1971).

The observation that ultrastructural changes did not occur uniformly throughout any population of fibroblasts indicates the need for quantitation in studies of fibroblast viability. We estimated the proportion of cells affected by each change by means of a detailed examination of 15 consecutive cells in each specimen. Tissue culture methods (Mohri et al., 1967; Angell et al., 1973 ; Al-Janabi et al., 1972; Lockey et al., 1972) can provide unequivocal evidence of cell viability, but the proportion and distribution of these cells are not determined. Autoradiography with tritiated thymidine has also been used to investigate the effects of preservation procedures on heart valve fibroblasts (Al-Janabi et al., 1972; Lockey et al., 1972). This technique labels only those cells which are synthesizing nucleic acids in the ' $S$ ' phase of their cell cycle and thus would label a higher proportion of cells in growing valves than in mature valves be cause of differences in the rate of cell proliferation and turnover. However, the use of the collagen precursor tritiated proline in such studies could provide valuable information about the functional capacity of heart valve fibroblasts, both during preservation procedures and subsequent to grafting.

Our histopathological studies of both antibiotictreated (Gavin, Herdson, Monro, and BarrattBoyes, 1973) and 'fresh' (Gavin, Barratt-Boyes, Hitchcock, and Herdson, 1973) human allografts suggest that donor fibroblasts disappear within weeks of grafting. This is inconsistent with the 
findings of other authors (Angell et al., 1972; 1973) who describe mitosis and synthesis of collagen and acid mucopolysaccharides by donor fibroblasts within the graft. Further studies utilizing a combination of ultrastructural, autoradiographic, and tissue culture methods are therefore required finally to determine the effects of preservation procedures and also of the immunological mechanisms of the recipient (Mohri et al., 1967 ; Buch, Kosek, Angell, and Shumway, 1971) on the fibroblasts of heart valve allografts.

We are most grateful to Mr. D. Baird, Miss $\mathbf{M}$. Strickett, Mr. C. J. A. Barber, and Miss L. A. Taylor for their assistance in this study and to Professor P. B. Herdson and Sir Brian Barratt-Boyes for their comments on the manuscript. This investigation was supported by grants from the Auckland Medical Research Foundation and the Medical Research Council of New Zealand.

\section{REFERENCES}

Al-Janabi, N., Gonzalez-Lavin, L., Neirotti, R., and Ross, D. N. (1972). Viability of fresh aortic valve homografts: a quantitative assessment. Thorax, 27, 83.

Angell, W. W., de Lanerolle, P., and Shumway, N. E. (1973). Valve replacement: Present status of homograft valves. Progress in Cardiovascular Diseases, 15, 589.

- Mermet, B., and Buch, W. (1970). Antibiotic sterilization of fresh homograft valves. Circulation, 42, Suppl. 3, p. 130.

, Shumway, N. E., and Kosek, J. C. (1972). A five-year study of viable aortic valve homografts. Journal of Thoracic and Cardiovascular Surgery, 64, 329.
Barratt-Boyes, B. G., and Roche, A. H. G. (1969). A review of aortic valve homografts over a six and one-half year period. Annals of Surgery, 170, 483.

Buch, W. S., Kosek, J. C., Angell, W. W., and Shumway, N. E. (1971). The role of rejection and mechanical trauma on valve graft viability. Journal of Thoracic and Cardiovascular Surgery, 62, 696.

Gavin, J. B., Barratt-Boyes, B. G., Hitchcock, G. C., and Herdson, P. B. (1973). The histopathology of 'fresh' human aortic valve allografts. Thorax, 28, 482.

- Herdson, P. B., and Barratt-Boyes, B. G. (1972). The pathology of chemically-sterilized human heart valve allografts. Pathology, 4, 175.

- - Herdson, P. B., Monro, J. L., and Barratt-Boyes, B. G. (1973). The pathology of antibiotic treated human heart valve allografts. Thorax, 28, 473.

Hanks, J. H. (1948). The longevity of chick tissue cultures without renewal of medium. Journal of Cellular and Comparative Physiology, 31, 235.

Hudson, R. E. B. (1966). Pathology of the human aortic valve homograft. British Heart Journal, 28, 291.

Kosek, J. C., Iben, A. B., Shumway, N. E., and Angell, W. W. (1969). Morphology of fresh heart valve homografts. Surgery, 66, 269.

Lockey, E., Al-Janabi, N., Gonzalez-Lavin, L., and Ross, D. N. (1972). A method of sterilizing and preserving fresh allograft heart valves. Thorax, 27, 398.

Mohri, H., Reichenback, D. D., Barnes, R. W., Nelson, R. J., and Merendino, K. A. (1967). Studies of antigenicity of the homologous aortic valve. Journal of Thoracic and Cardiovascular Surgery, 54, 564.

Trump, B. F., and Arstila, A. U. (1971). Cell injury and cell death. In: Principles of Pathobiology, edited by M. F. LaVia, and R. B. Hill, pp. 9-95. Oxford University Press, New York.

chemical consequences of cell injury. The Inflammatory Process, edited by B. W. Zweifach, L. Grant, and R. T. McCluskey, pp. 35-120. Academic Press, New York. 